\title{
Characterization of Late Blight Resistance Derived from Solanum pimpinellifolium L3708 against Multiple Isolates of the Pathogen Phytophthora infestans
}

\author{
Min-Jea Kim ${ }^{1}$ and Martha A. Mutschler ${ }^{2}$ \\ Department of Plant Breeding, Cornell University, Ithaca, NY 14853
}

\begin{abstract}
AdDitional INDEX WORDs. Lycopersicon esculentum, tomato, disease resistance, dominance
Abstract. Sixteen tomato [Solanum lycopersicum L. (syn. Lycopersicon esculentum Mill.)] genotypes (inbred lines or hybrids) were tested against five Phytophthora infestans (Mont.) deBary isolates to characterize race specificity of late blight resistance transferred to tomato from Solanum pimpinellifolium $\mathrm{L}$. [syn. Lycopersicon pimpinellifolium (L.) Mill.] accession L3708. The effects of plant genotype, isolate, genotype $\times$ isolate, and isolate $\times$ replication interactions were highly significant $(P=\mathbf{0 . 0 0 1})$. Set of four sister lines fixed for late blight resistance $(C U-R$ lines $)$ exhibited full and equal resistance to the five pathogen isolates tested. In contrast, the heterozygous $F_{1}$ hybrids, created by crossing the resistant CU-R lines with a susceptible parent, were resistant to US-11; partially resistant to US-17, NC-1, and DR4B; and susceptible to US-7. Differential responses were also observed across pathogen isolates on a set of resistant sister lines (CLN-R lines), which also were bred from L3708. The CLN-R lines were resistant to the DR4B, NC-1, and US11 isolates, but showed significant disease-affected areas and sporangium numbers following inoculation with either US-7 or US-17. Restriction fragment length polymorphism (RFLP) analysis confirms that both CU-R and CLN-R are homozygous for the Ph-3 gene derived from L3708. Since progeny tests also confirmed that the CLN-R lines are fixed for their level of resistance, these results suggest that late blight resistance in the CU-R lines is not controlled by $P h-3$ alone, and that at least one additional gene conferring late blight resistance is missing from the CLN-R lines. Results of genetic tests of the (CU-R x CLN-R) $F_{1}$ and a (CU-R x CLN-R) $F_{2}$ population with the pathogen isolate US-17 strongly support a model in which resistance of the CU-R lines requires genes in addition to $P h-3$. The implications of this information in breeding for late blight resistance and using of the resulting resistant lines or hybrids are discussed.
\end{abstract}

Late blight, caused by the fungal pathogen Phytophthora infestans, results in severe loss of tomato production in environments favorable to disease development. Late blight control is increasingly difficult due to changes in $P$. infestans pathogenicity, the introduction of new pathogen isolates, and increased resistance of the pathogen to fungicides (Fry and Goodwin, 1997a, 1997b; Goodwin et al., 1998; Kato et al., 1997). Tomato losses due to this disease can be substantial, despite efforts to forecast weather conditions favorable to late blight development and the availability of chemicals to control infection (Davis et al., 1996, 1998; Raposo et al., 1993).

Late blight control through plant resistance is an attractive alternative to reliance on chemical control. Two previously described late blight resistance genes, $P h-1$ (Bonde and Murphy, 1952) and $P h-2$ (Gallegly, 1960; Peirce, 1970, 1971), were derived from Solanum pimpinellifolium. Resistance conferred by $P h-1$, a dominant race-O specific allele (Bonde and Murphy, 1952), was rapidly overcome due to the race specificity of this gene (Conover

Received for publication 1 Aug. 2005. Accepted for publication 4 May 2006. We thank Drs. Peter Hanson and Lowell Black for generously sharing the resistance source L3708, and providing seed of the late blight-resistant lines developed at the Asia Vegetable Research Development Center (AVRDC). We thank Dr. Randy Gardner for discussion over the course of this work. We also thank Dr. William Fry for the P. infestans isolates he provided and for his advice on their culture. This project was supported by gift funds from the California League of Food Processors and from USDA HATCH project number 149484, and also by a grant of the BioGreen21 program (200504010348240060600) from the rural Development Administration in Korea.

'Current address: Division of Environmental and Life Sciences, Seoul Women's University, Seoul 139-774, Korea

2Towhom reprint requests should be addressed.E-mail address:mam13@cornell. edu and Walter, 1952, 1953; Gallegly, 1952). $P h$-2 is a partially dominant allele that confers resistance to late blight (Gallegly, 1960; Peirce, 1970, 1971), though other loci are believed to contribute to this dominance (N. Grimsley, personal communication). The level of disease suppression conditioned by $P h-2$ is affected by additional factors (Laterrot, 1975; Turkensteen, 1973), and the resistance is not effective across a number of pathogen isolates (Goodwin et al., 1995). Therefore, neither $P h-1$ nor $P h-2$ is widely used in tomato breeding and there are currently no tomato cultivars resistant across $P$. infestans isolates. Since the tomato and potato (Solanum tuberosum L.) are closely related and have very similar genomes (Tanksley et al., 1992), it is useful to also consider late blight resistance genes of potato. Each of the major P. infestans resistance genes of potato, $\mathrm{R} 1$ through $\mathrm{R} 11$, is a single dominant race-specific allele (Malcolmson and Black, 1966; Trognitz et al., 2002; Wastie, 1991). Recently, a single dominant late blight resistance gene was found in Solanum bulbocastanum Dun. and quantitative resistance genes were found in Solanum berthaultii Hawkes (Ewing et al., 2000; Naess et al., 2000, 2001).

After screening an expanded series of tomatorelatives, researchers at the Asia Vegetable Research Development Center(AVRDC) in Tainan, Taiwan, identified S. pimpinellifolium accession L3708 [also known as LA1269 (C.M. Rick Tomato Genetics Resource Center, Davis, Calif.) and U.S. Dept. of Agriculture (USDA) accessions NSL116890 and PI365957] as having strong resistance to late blight (AVRDC, 1994; Chunwongse et al., 2002). They generously provided L3708 to other breeding programs, which proceeded to transfer the resistance to tomato lines (AVRDC, 1999; Kim, 2003; Kim and Mutschler, 2005). When the resulting lines were grown together under natural infection, their degree of late blight resistance differed among the lines bred by different 
programs (R. Gardner, personal communication). Segregation data obtained while breeding with this source of late blight resistance also suggested the possibility of differential response of homozygous vs. heterozygous plant genotypes to several pathogen isolates (Kim, 2003; Kim and Mutschler, 2005). A more complete examination of these differences in disease response could help design optimal breeding strategies for transfer of the broadest resistance possible using this source of resistance, and determine the most reliable and stable means to deploy this resistance in commercial cultivars. The goals of these experiments include: testing independently developed tomato lines derived from L3708 for resistance to a spectrum of $P$. infestans isolates, determining whether race specificity for resistance can be demonstrated, analyzing the effect of homozygosity/heterozygosity for this resistance, and using genetic tests to determine whether multiple genes may be involved in the resistance of these lines.

\section{Materials and Methods}

Tomato Lines TESTED. Twenty-three tomato genotypes were tested against five late blight isolates. The tomato lines used as late blight susceptible controls were the open-pollinated fresh market line 'NC215E' (R. Gardner, North Carolina State Univ., Raleigh), the open-pollinated processing tomato line 'E6203' (LA4024; C.M. Rick Tomato Genetics Resource Center) and the hybrid processing tomato 'Hypeel 45' (Seminis, Oxnard, Calif.).

The tomato lines 'New Yorker' (LA2009; C.M. Rick Tomato Genetics Resource Center) and 'West Virginia 63' (PI 367956; USDA, Agricultural Research Service, National Center for Genetic Resources Preservation, Fort Collins, Colo.) were used as controls in these experiments since they possess the $P h-1$ and $P h$-2 late blight resistance genes, respectively (Moreau et al., 1998; Peirce, 1970). The resistance of L3708 was transferred into a series of processing tomato lines by the Cornell Univ. breeding program (Kim, 2003; Kim and Mutschler, 2005), using, as the initial starting material, two late blight-resistant $\mathrm{BC}_{1} \mathrm{~F}_{2}$ plants ('97A46' and '97A48', respectively) provided by R. Gardner. Lines '97A46' and '97A48' are $\mathrm{BC}_{1} \mathrm{~F}_{2}$ plants from the pedigree 'NC215E' x ('NC215E' x S. pimpinellifolium L 3708) selected as late blight resistant under natural infection (R. Gardner, personal communication). The four resistant processing tomato CU-R lines used in these experiments were '993141-7' and '9931865', which were derived from '97A46', and '993104-10' and '993111-7', which were derived from '97A48'. Selection for late blight resistance in the Cornell breeding program was based upon disease screens using P. infestans isolates US-7 and US-17, and the resulting lines were fully resistant to both of these isolates (Kim and Mutschler, 2005).

Experimental hybrids were also generated for use in this study. The late blight-resistant CU-R lines '993141-7' and '993104-10' were crossed as the male parent to the susceptible tomato lines 'E6203' and 'NC215E', resulting in four hybrids heterozygous for the late blight resistance gene(s) carried by the resistant parents. The hybrid '993104-10' X '993141-7' was used as an $F_{1}$ hybrid that is homozygous for the late blight resistance genes carried by each parent.

Two late blight-resistant CLN-R lines, 'CLN2037B' and 'CLN2037E' (P. Hanson and L. Black, AVRDC), which also carry late blight resistance from L3708 (AVRDC, 1998), were used in an initial test to represent independently bred lines. In a second test, the self-progeny of two selections, each from the 'CLN2037B' and 'CLN2037E' lines, and an additional seven CLN-
Rlines ('CLN2037A', 'CLN2037C', 'CLN2037D', 'CLN2037F', 'CLN2037G', 'CLN2037H', 'CLN2037I') were tested to broaden representation of this family of lines.

$F_{1}$ HYBRID AND $F_{2}$ POPULATION USED FOR GENETIC TESTS. To test whether more than one gene controls the broad resistance observed in CU-R lines, the CU-R '993186-5' line and the 'CLN2037B' line were crossed, and the resulting $\mathrm{F}_{1}$ population was tested, along with susceptible controls, for resistance to US-17, an isolate that discriminates between resistance of the CU-R and CLN lines. Six plants per each genotype were tested using the droplet method followed by sporangium counts. After this test, one of $F_{1}$ plant was self-pollinated to produce $\mathrm{F}_{2}$ seeds. An $\mathrm{F}_{2}$ population of 144 plants was subsequently tested, along with parent plants as controls, to examine resistance segregation following a challenge using the US-17 isolate.

Plant growth conditions. Tomato seeds were sown in 72-cell Speedling trays (Sun City, Fla.) containing Cornell soil mix (Boodley and Sheldrake, 1973). At $\approx 6$ weeks, plants were transplanted to 15.2-cm-diameter clay pots containing Cornell soil mix. The number of plants grown per line or population varied by experiment and is provided in the analysis tables. Plants were grown in greenhouse at $25^{\circ} \mathrm{C} 16 \mathrm{~h}$ with a daily 16 -h light period and they were fertilized periodically with $15 \mathrm{~N}-2.2 \mathrm{P}-12.5 \mathrm{~K}$ watersoluble fertilizer (Peters 15-5-15; The Scotts Co., Marysville, Ohio). Plants were staked to prevent contact with the ground and the spread of disease. Chemical control agents were not sprayed onto the plants since these might affect test results.

RFLP TEST OF TOMATo LINES. $P h-3$, the major late blight resistance gene from L3708, was mapped to the bottom of chromosome 9 by Chunwongse et al. (2002). We used RFLP analysis with a marker closely lined to $P h-3$ (TG591A) to confirm the presence of $P h-3$ and its homozygosity in all of CU-R and CLN-R lines used.

Pathogen isolates USEd In disease SCReens. Phytophthora infestans isolates US-7, US-11, US-17, NC-1, and DR4B were obtained from W. Fry (Cornell Univ., Ithaca, N.Y.) to provide pathogen diversity for these screens. US-7 is an older isolate that once was dominant throughout the United States, but that has largely been replaced by newer isolates. US-11 is a major isolate in California, while NC-1 is a dominant isolate in North Carolina. US-17 is a recent isolate in southeastern United States and along the east coast to New Jersey and New York (Fry and Goodwin, 1997). The isolate DR4B was collected from the Dominican Republic (W. Fry, personal communication). Isolates were classified by RG57 fingerprinting and allozyme genotyping (Fraser et al., 1999; Goodwin et al., 1998). US-7 and NC-1 are of the A2 mating type while the other isolates are of the A1 mating type; all of the U.S. isolates are metalaxyl resistant, but the response of DR4B to metalaxyl is unknown (Fraser et al., 1999; Goodwin et al., 1998).

Culture maintenance and inoculum preparation. Phytophthora infestans isolates were sub-cultured each month on rye B (Caten and Jinks, 1968). Sporangia were isolated from culture plates with double-distilled $\mathrm{H}_{2} \mathrm{O}$ and concentrated with brief centrifugation. Leaflets of the susceptible tomato cultivar VFT Vendor were inoculated with the concentrated sporangia to increase sporangium numbers and eliminate the possibility of attenuated pathogenicity. Leaflets were placed adaxial surface down on lids of water agar plates, then inoculated with a suspension of concentrated sporangia, and covered by a petri dish bottom containing water agar to maintain a relative humidity $(\mathrm{RH})$ near $100 \%$. The plates were incubated upside down for 6 or $7 \mathrm{~d}$ at 18 
${ }^{\circ} \mathrm{C}$ with a daily 16 -h light period. Sporangium concentrations were adjusted to 40,000 sporangia/mL.

InOCULATION AND DATA COLLECTION. Detached leaflet droplet tests (Legard et al., 1995) were modified to test late blight resistance. The first experiments were replicated three times using six plants of each genotype; in all, 1260 leaflets were tested. Subsequently, 16 plants of each genotype were used to test an expanded set of CLN-R lines, and progeny of selections from 'CLN2037B' and 'CLN2037E'. Since full activation of $P h-2$ gene occurs 6 weeks after germination (Turkensteen, 1973), all leaflet samples were taken from plants at least 6 weeks old. Leaflets were collected from the third or fourth leaf from the stem apex to synchronize leaflet age and size. Leaflets were placed into the lids of water agar plates and then the abaxial surface of each leaflet was inoculated with two $20-\mu \mathrm{L}$ drops of the sporangium suspension described above. The leaflets were incubated for 6 or 7 $\mathrm{d}$ using the conditions described above for increasing the number of sporangia. Leaflets were visually evaluated for hyphal growth and digitally photographed (Kodak DC260; Eastman Kodak Co., Rochester, N.Y.). A ruler was included in the photographs to facilitate determination of diseased leaflet area. Diseased area was measured and calculated using the UTHSCSA Image tool version 2.02 developed by the Univ. of Texas Health and Science Center, San Antonio.

Following the collection of visual data, leaflets were placed into a $5-\mathrm{mL}$ preservation solution consisting of sodium acetate and copper sulfate, and mixed for $10 \mathrm{~s}$ using a vortex (Mizubuti and Fry, 1998). Leaflets were removed from the solution, which was stored at $4^{\circ} \mathrm{C}$ until sporangium numbers were counted using a 0.2-mm-deep hemocytometer (Hausser Scientific, Horsham, Pa.).

The detached-leaflet dipping test is a modification of the droplet test. Leaflets were collected for the dipping test as described for the droplet test. The distal tip half of each leaflet was dipped into suspension of 40,000 sporangia/mL, and the leaflets were incubated as described for the detached droplet test. Data for the dipping test was collected solely by visual evaluation of leaflets since the number of sporangia applied is not tightly controlled. The dipping test is advantageous in that it can be performed more rapidly than the droplet test, facilitating the large-scale screening of leaflets. Prior work comparing these two assays demonstrated that both techniques provided equivalent results in the classification of resistant and susceptible plants (M.J. Kim and M.A. Mutschler, unpublished results).

Data AnAlysis. Analysis of variance (ANOVA) and Tukey's Studentized range test were used to analyze data. The collected spore number and diseased leaflet area, and the calculated sporangium number/diseased area $\left(\mathrm{cm}^{2}\right)$ were analyzed as randomized complete-block designs using SAS (SAS Institute, Cary, N.C.) for ANOVA. Single effects of genotype, isolate, replication, and two- and three-factor interactions were analyzed. For variable stabilizing transformation, data were natural log transformed using $\mathrm{Y}=\mathrm{LN}(\mathrm{X}+1)$ equation before analysis.

For the full model ANOVA, we used the corrected residual error as the error term, which combined differences among plants within same genotype and between the replicate differences (Kim, 2003). This resulted in corrected $F$ values, which were used to calculate $\mathrm{P}$ values. After the $\mathrm{F}$ values were corrected, a comparison with other factors, and of the interactions among factors could be performed. After the ANOVA test was performed, Tukey's Studentized range test was used for grouping genotypes by various conditions to verify susceptibility and resistance level.

\section{Results}

Testing 16 tomato genotypes against five Pathogen isoLATES. Clear differences in average diseased leaflet area $\left(\mathrm{cm}^{2}\right)$ and average sporangium number were observed among tomato lines and hybrids tested using five isolates (Fig. $1 \mathrm{~A}$ and B). The susceptible lines were all highly susceptible, with diseased areas that often extended throughout the leaflet (Fig. 1A). The disease level of the $P h-1$ line 'New Yorker' was similar to that of the susceptible controls for each of the five isolates tested. The level of disease observed in the $P h-2$ line 'West Virginia 63' was similar to that of the susceptible controls when challenged with US-7, DR4B and NC-1, but lower than that of the susceptible controls when challenged with US-11 or US-17.

The diseased leaflet areas of the four late blight-resistant CU-R lines and the homozygous resistant $\mathrm{F}_{1}$ (the hybrid between two late blight-resistant fixed CU-R lines) were all very low, showing equally strong resistance against the five of the pathogen isolates tested. In contrast, the disease response of the four heterozygous hybrids differed depending on the pathogen isolate used. The heterozygous hybrids had minimal levels of diseased area when inoculated with US-11 and DR4B, intermediate levels of diseased area when inoculated with US-17 and NC-1, and levels of diseased area near that of susceptible controls when inoculated with US-7 (Fig. 1A). Two late blight-resistant CLN-R lines, 'CLN2037B' and 'CLN2037E', also produced a different disease response depending on the pathogen isolate used. The CLN-R lines had minimal levels of diseased area when inoculated with US-11 or DR4B, intermediate levels of diseased area when inoculated by US-17 and NC-1, and levels of diseased area near that of susceptible controls when inoculated with US-7.

Clear differences in average sporangium numbers were observed among tomato lines and hybrids. The susceptible lines had high levels of sporangia with absolute numbers varying depending on the isolate tested (Fig. 1B). A similar pattern of high sporangium production was observed when the 'New Yorker' and 'West Virginia 63' tomato lines were inoculated with isolates US-7, NC-1, and DR4B; a lower level of sporangium production was observed when these lines were inoculated with US-17.

Counts of the average number of sporangia produced on the four CU-R lines and on the homozygous resistant $F_{1}$ hybrids were all extremely low when inoculated with any of the isolates tested. This is in agreement with results for the average diseased area found on these tomato genotypes following inoculation with any of the five isolates. In contrast, the results for the average number of sporangia found on the heterozygous tomato hybrids differed from the results of the diseased area found on these genotypes. Heterozygous hybrids were as resistant to US-11 as the homozygous CU-R parent lines, and exhibited low to moderate sporangium numbers in response to US-17, NC-1, and DR4B. The heterozygous hybrids exhibited the highest sporangium numbers when inoculated with US-7 (Fig. 1B). The disease response of the two CLN-R lines was not uniform across isolates, with the highest sporangium numbers produced when leaflets were inoculated with US-7 (Fig. 1B). Sporangium number/diseased area $\left(\mathrm{cm}^{2}\right)$ was also considered, but this metric produced a figure that is essentially the same as that for sporangium numbers (data not shown).

Data for sporangium counts, diseased area, and sporangium number/diseased area $\left(\mathrm{cm}^{2}\right)$ were analyzed by ANOVA to test the significance of the differences observed among genotypes tested, and the effect of factors such as variation within a genotype, the genotype groupings and the interaction among factors. The 

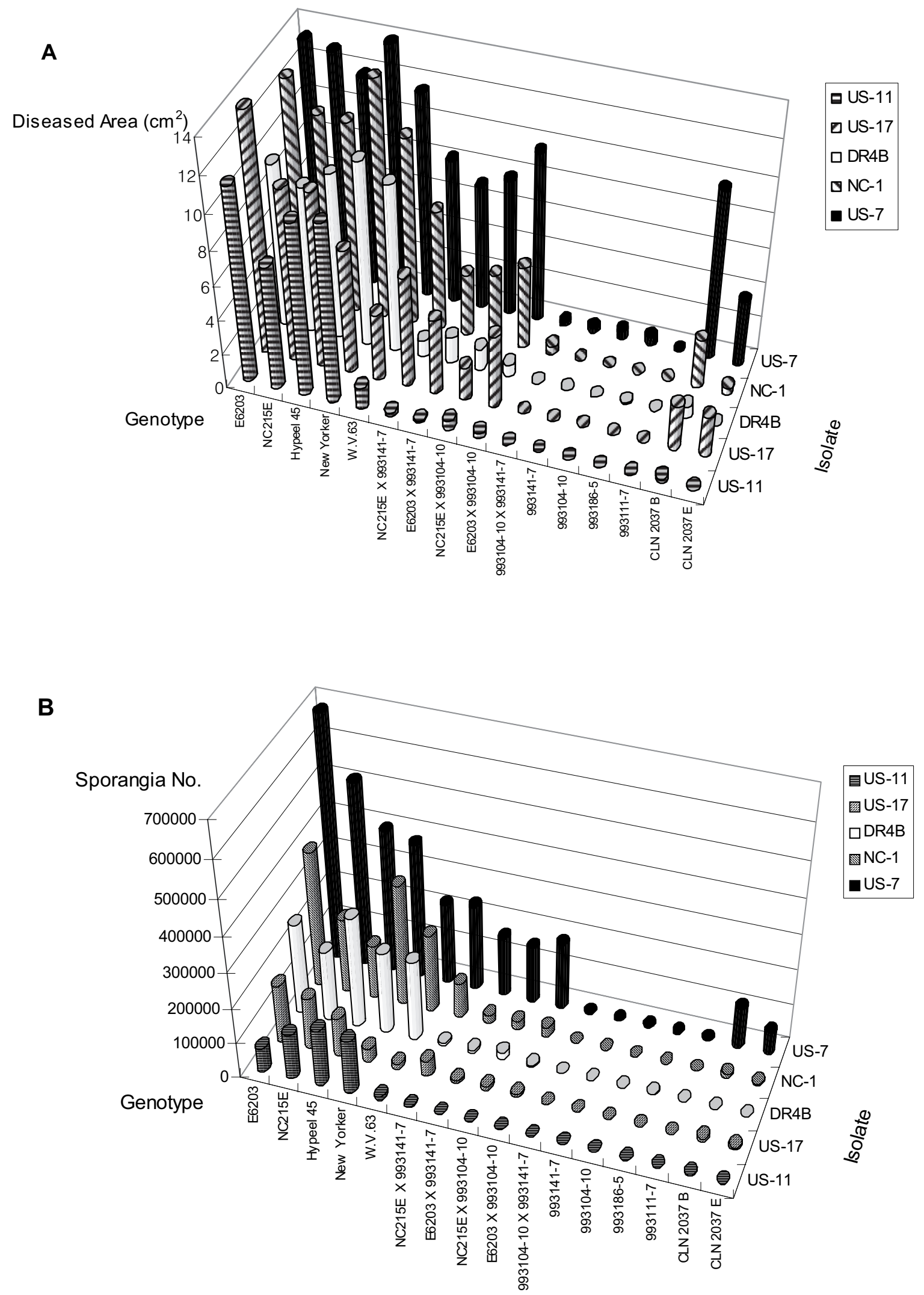

Fig. 1. Late blight disease response as measured by $(\mathbf{A})$ average diseased area $\left(\mathrm{cm}^{2}\right)$ and $(\mathbf{B})$ average sporangium number in detached leaflet droplet tests of 16 tomato genotypes using five pathogen isolates. Tomato genotypes used include susceptible controls ('E6203', 'NC215E', 'Hypeel 45'), the Ph-1 control ('New Yorker'), the $P h-2$ control ('W.V.63'), two late blight-resistant CLN-R lines ('CLN2037B' and 'CLN2037E'), four late blight-resistant CU-R lines ('992141-7', '99310410', '993186-5', '992111-7') (CU-R and CLN-R = two independently bred sets of tomato lines developed using L3708 as a source of late blight resistance), one homozygous resistant $F_{1}$ hybrid from the cross of two CU-R lines ('993104-10' $x$ '993141-7'), and four heterozygous resistant $F_{1}$ hybrids resulting from the cross of a susceptible line ('NC215E' or 'E6203'), and a resistant parent line ('993104-10' or '993141-7'). 
ANOVA results (Table 1) indicated the overall reliability of these experiments as well as clear differences among the genotypes and isolates tested (Table 1). Plant genotype, isolate, genotype $x$ isolate interaction and isolate $x$ replication interactions were all highly significant at $P=0.001$.

Since the ANOVA test strongly supported overall differences in genotype-dependent response, Tukey's Studentized range test was performed on the data to determine how the genotypes differ in response to each of the isolates. The results of analysis of average number of sporangia produced (Table 2), the diseased area (Table 3$)$, and sporangium number/diseased area $\left(\mathrm{cm}^{2}\right)(\mathrm{Kim}$, 2003, not shown) data gave the similar results for the five isolates, therefore these analyses can be considered simultaneously. The responses of the resistant genotypes differed significantly from that of the susceptible controls. Ph-1 grouped with susceptible controls for all five pathogen isolates tested, while $P h$-2 grouped with susceptible controls in tests using the DR4B, NC-1, and US-7 isolates, but grouped with the heterozygous $F_{1}$ hybrids in tests using the US-17 and US-7 isolates. For isolates US-17, DR4B and NC-1, the heterozygous $\mathrm{F}_{1}$ hybrids grouped between susceptible controls and resistant lines, but grouped closer to susceptible lines indicating a partially dominant resistance. The heterozygous $\mathrm{F}_{1}$ hybrids and the resistant fixed CU-R lines, however, grouped together against US-11, indicating a completely dominant resistance, while the heterozygous $F_{1}$ hybrids and the susceptible controls were grouped together against US-7, indicating a recessive resistance.

For sporangium results (Table 2), both CLN-R lines differed from the resistant fixed CU-R lines for isolate US-7, while 'CLN2037B' differed from the CU-R lines for isolates US-17 and $\mathrm{NC}-1$. In each of these instances, the response of the CLN lines grouped with the heterozygous $F_{1}$ hybrids. The data for

Table 1. Summary of ANOVA test of late blight disease response as measured by sporangium number, diseased area, and sporangium numbers/diseased area $\left(\mathrm{cm}^{2}\right)$ in detached leaflet droplet tests of 16 tomato genotypes using five pathogen isolates.

\begin{tabular}{|c|c|c|c|c|c|c|c|}
\hline \multirow[b]{2}{*}{ Source } & \multirow[b]{2}{*}{$\mathrm{df}$} & \multicolumn{2}{|c|}{ Sporangium no. ${ }^{z}$} & \multicolumn{2}{|c|}{ Diseased area ${ }^{z}$} & \multicolumn{2}{|c|}{$\begin{array}{c}\text { Sporangia no./ } \\
\text { diseased area }\end{array}$} \\
\hline & & MS & Corrected Fy & MS & Corrected Fy & MS & Corrected Fy \\
\hline Genotype (G) & 15 & 1945.26 & $142.15^{* * * *}$ & 81.56 & $132.60^{\text {**** }}$ & 1257.34 & $133.08^{* * * *}$ \\
\hline Isolate (I) & 4 & 897.89 & $65.61^{* * * *}$ & 36.08 & $58.66^{* * *}$ & 589.46 & $62.39^{* * * *}$ \\
\hline Replication $(\mathrm{R})^{\mathrm{y}}$ & 2 & 20.07 & 1.47 & 2.22 & $3.61^{*}$ & 12.05 & 1.28 \\
\hline $\mathrm{G} \times \mathrm{I}$ & 60 & 76.95 & $5.62^{* * *}$ & 3.14 & $5.10^{* * *}$ & 50.87 & $5.38^{* * *}$ \\
\hline $\mathrm{G} \times \mathrm{R}$ & 30 & 14.83 & 1.08 & 0.52 & 0.84 & 10.95 & 1.16 \\
\hline $\mathrm{I} \times \mathrm{R}$ & 8 & 70.55 & $5.16^{* * * *}$ & 3.27 & $5.31^{* * * *}$ & 45.45 & $4.81^{* * * *}$ \\
\hline $\mathrm{G} \times \mathrm{I} \times \mathrm{R}(\mathrm{R} 2$ vs. $\mathrm{R} 3)$ & 60 & 16.04 & 1.17 & 0.70 & 1.16 & 10.69 & 1.13 \\
\hline Residual (error) & 60 & 13.68 & & 0.62 & & 9.45 & \\
\hline
\end{tabular}

${ }^{\mathrm{z} A n a l y s i s}$ performed upon the natural log of sporangium number or disease area.

yAnalysis based upon corrected $\mathrm{F}$ as detailed in materials and methods.

*,**,***Values are significant at $P \leq 0.05,0.01$, and 0.001 , respectively.

Table 2. Tukey's Studentized range (honestly significant difference) test of late blight disease response as measured by average sporangium numbers ${ }^{z}$ generated from detached leaflet droplet tests of 16 tomato genotypes using five pathogen isolates.

\begin{tabular}{lccccccc}
\hline Genotype name & Class $^{y}$ & All isolates $^{\mathrm{x}}$ & US-11 $^{\mathrm{w}}$ & US-17w $^{\mathrm{w}}$ & DR4B $^{\mathrm{w}}$ & NC-1w $^{\mathrm{w}}$ & US-7 $^{\mathrm{w}}$ \\
\hline E6203 & $\mathrm{S}$ & $11.92 \mathrm{a}$ & $10.76 \mathrm{a}$ & $11.40 \mathrm{a}$ & $12.27 \mathrm{a}$ & $12.31 \mathrm{a}$ & $12.85 \mathrm{a}$ \\
NC215E & $\mathrm{S}$ & $11.97 \mathrm{a}$ & $11.48 \mathrm{a}$ & $11.12 \mathrm{ab}$ & $12.00 \mathrm{a}$ & $12.02 \mathrm{a}$ & $13.21 \mathrm{a}$ \\
Hypeel 45 & $\mathrm{S}$ & $11.70 \mathrm{a}$ & $11.57 \mathrm{a}$ & $10.28 \mathrm{a}-\mathrm{c}$ & $12.43 \mathrm{a}$ & $11.58 \mathrm{a}$ & $12.62 \mathrm{a}$ \\
New Yorker & $P h-1$ & $11.27 \mathrm{a}$ & $11.40 \mathrm{a}$ & $7.80 \mathrm{~b}-\mathrm{d}$ & $11.93 \mathrm{a}$ & $12.51 \mathrm{a}$ & $12.70 \mathrm{a}$ \\
W.V.63 & $P h-2$ & $8.66 \mathrm{~b}$ & $2.35 \mathrm{~b}$ & $5.03 \mathrm{~d}-\mathrm{f}$ & $11.79 \mathrm{a}$ & $11.92 \mathrm{a}$ & $12.21 \mathrm{ab}$ \\
NC215E x 993141-7 & $\mathrm{F}_{1}$ & $6.64 \mathrm{c}$ & $0.53 \mathrm{~cd}$ & $6.95 \mathrm{c}-\mathrm{e}$ & $2.81 \mathrm{bc}$ & $10.84 \mathrm{a}$ & $12.09 \mathrm{ab}$ \\
E6203 x 993141-7 & $\mathrm{F}_{1}$ & $4.91 \mathrm{~d}$ & $0.46 \mathrm{~cd}$ & $4.53 \mathrm{~d}-\mathrm{f}$ & $3.72 \mathrm{~b}$ & $5.94 \mathrm{~b}$ & $9.90 \mathrm{bc}$ \\
NC215E x 993104-10 & $\mathrm{F}_{1}$ & $4.89 \mathrm{de}$ & $1.46 \mathrm{bc}$ & $1.75 \mathrm{fg}$ & $4.07 \mathrm{~b}$ & $6.20 \mathrm{~b}$ & $10.96 \mathrm{a}-\mathrm{c}$ \\
E6203 x 993104-10 & $\mathrm{F}_{1}$ & $5.32 \mathrm{~d}$ & $0.87 \mathrm{~cd}$ & $4.73 \mathrm{~d}-\mathrm{f}$ & $2.62 \mathrm{bc}$ & $6.86 \mathrm{~b}$ & $11.54 \mathrm{a}-\mathrm{c}$ \\
993104-10 x 993141-7 & $\mathrm{R} \times \mathrm{R}$ & $0.36 \mathrm{~g}$ & $0.00 \mathrm{~d}$ & $0.00 \mathrm{~g}$ & $0.00 \mathrm{~d}$ & $0.93 \mathrm{~cd}$ & $0.86 \mathrm{e}$ \\
993141-7 & $\mathrm{R}$ & $0.08 \mathrm{~g}$ & $0.00 \mathrm{~d}$ & $0.00 \mathrm{~g}$ & $0.00 \mathrm{~d}$ & $0.00 \mathrm{~d}$ & $0.40 \mathrm{e}$ \\
993104-10 & $\mathrm{R}$ & $0.11 \mathrm{~g}$ & $0.00 \mathrm{~d}$ & $0.00 \mathrm{~g}$ & $0.00 \mathrm{~d}$ & $0.00 \mathrm{~d}$ & $0.54 \mathrm{e}$ \\
993186-5 & $\mathrm{R}$ & $0.29 \mathrm{~g}$ & $0.00 \mathrm{~d}$ & $0.00 \mathrm{~g}$ & $0.52 \mathrm{~cd}$ & $0.00 \mathrm{~d}$ & $0.94 \mathrm{e}$ \\
993111-7 & $\mathrm{R}$ & $0.00 \mathrm{~g}$ & $0.00 \mathrm{~d}$ & $0.00 \mathrm{~g}$ & $0.00 \mathrm{~d}$ & $0.00 \mathrm{~d}$ & $0.00 \mathrm{e}$ \\
CLN2037B & $\mathrm{C}$ & $3.70 \mathrm{e}$ & $0.47 \mathrm{~cd}$ & $3.81 \mathrm{ef}$ & $0.98 \mathrm{~cd}$ & $3.82 \mathrm{bc}$ & $9.40 \mathrm{c}$ \\
CLN2037E & $\mathrm{C}$ & $1.88 \mathrm{f}$ & $0.00 \mathrm{~d}$ & $2.64 \mathrm{fg}$ & $0.00 \mathrm{~d}$ & $1.85 \mathrm{~cd}$ & $4.90 \mathrm{~d}$ \\
Error mean square & & 5.97 & 2.67 & 9.35 & 5.06 & 7.42 & 5.38 \\
Minimum significant difference & 1.25 & 1.89 & 3.53 & 2.60 & 3.14 & 2.68 \\
\hline
\end{tabular}

${ }^{\mathrm{z}}$ Analysis performed upon the natural $\log$ of sporangium number.

y $\mathrm{S}=$ susceptible checks, $\mathrm{R}=$ resistant fixed CU-R lines, $\mathrm{C}=\mathrm{CLN}-\mathrm{R}$ lines $(\mathrm{CU}-\mathrm{R}$ and CLN-R $=$ two independently bred sets of tomato lines developed using L3708 as a source of late blight resistance), $\mathrm{F}_{1}$ = heterozygous $\mathrm{F}_{1}$ hybrid between resistant fixed CU-R lines $\mathrm{x}$ susceptible checks, $\mathrm{R} \times \mathrm{R}=$ homozygous $\mathrm{F}_{1}$ hybrid between resistant fixed CU-R lines.

${ }^{x} \alpha=0.05, \mathrm{~N}=90$, error $\mathrm{df}=1050$, critical value of Studentized range $=4.75$.

${ }^{\mathrm{w}} \alpha=0.05, \mathrm{~N}=18$, error $\mathrm{df}=240$, critical value of Studentized range $=4.90$. 
Table 3. Tukey's Studentized range (honestly significant difference) test of late blight disease response as measured by diseased leaflet area $^{z}$ generated from detached leaflet droplet tests of 16 tomato genotypes with five pathogen isolates.

\begin{tabular}{lcclllll}
\hline Genotype name & Class $^{y}$ & All isolates $^{\mathrm{x}}$ & US-11 $^{\mathrm{w}}$ & US-17w $^{\mathrm{w}}$ & DR4B $^{\mathrm{w}}$ & ${\mathrm{NC}-1{ }^{\mathrm{w}}}^{\text {US-7w }^{\mathrm{w}}}$ \\
\hline E6203 & $\mathrm{S}$ & $2.54 \mathrm{a}$ & $2.48 \mathrm{a}$ & $2.64 \mathrm{a}$ & $2.31 \mathrm{a}$ & $2.58 \mathrm{ab}$ & $2.67 \mathrm{a}$ \\
NC215E & $\mathrm{S}$ & $2.32 \mathrm{a}$ & $2.03 \mathrm{~b}$ & $2.32 \mathrm{ab}$ & $2.18 \mathrm{a}$ & $2.46 \mathrm{ab}$ & $2.61 \mathrm{ab}$ \\
Hypeel 45 & $\mathrm{S}$ & $2.38 \mathrm{a}$ & $2.35 \mathrm{ab}$ & $2.29 \mathrm{ab}$ & $2.32 \mathrm{a}$ & $2.43 \mathrm{ab}$ & $2.51 \mathrm{ab}$ \\
New Yorker & $P h-1$ & $2.35 \mathrm{a}$ & $2.35 \mathrm{ab}$ & $1.70 \mathrm{bc}$ & $2.40 \mathrm{a}$ & $2.64 \mathrm{a}$ & $2.69 \mathrm{a}$ \\
W.V.63 & $P h-2$ & $1.74 \mathrm{~b}$ & $0.41 \mathrm{c}$ & $1.05 \mathrm{~cd}$ & $2.28 \mathrm{a}$ & $2.43 \mathrm{ab}$ & $2.54 \mathrm{ab}$ \\
NC215E x 993141-7 & $\mathrm{F}_{1}$ & $1.25 \mathrm{c}$ & $0.08 \mathrm{~cd}$ & $1.63 \mathrm{bc}$ & $0.40 \mathrm{bc}$ & $2.00 \mathrm{~b}$ & $2.15 \mathrm{a}-\mathrm{c}$ \\
E6203 x 993141-7 & $\mathrm{F}_{1}$ & $0.95 \mathrm{de}$ & $0.08 \mathrm{~cd}$ & $1.10 \mathrm{~cd}$ & $0.60 \mathrm{~b}$ & $1.08 \mathrm{c}$ & $1.87 \mathrm{c}$ \\
NC215E x 993104-10 & $\mathrm{F}_{1}$ & $0.90 \mathrm{de}$ & $0.25 \mathrm{~cd}$ & $0.42 \mathrm{de}$ & $0.55 \mathrm{~b}$ & $1.19 \mathrm{c}$ & $2.08 \mathrm{bc}$ \\
E6203 x 993104-10 & $\mathrm{F}_{1}$ & $1.05 \mathrm{~cd}$ & $0.13 \mathrm{~cd}$ & $1.11 \mathrm{~cd}$ & $0.35 \mathrm{bc}$ & $1.35 \mathrm{c}$ & $2.31 \mathrm{a}-\mathrm{c}$ \\
993104-10 x 993141-7 & $\mathrm{R} \times \mathrm{R}$ & $0.06 \mathrm{~g}$ & $0.00 \mathrm{~d}$ & $0.00 \mathrm{e}$ & $0.00 \mathrm{c}$ & $0.17 \mathrm{de}$ & $0.12 \mathrm{e}$ \\
993141-7 & $\mathrm{R}$ & $0.02 \mathrm{~g}$ & $0.00 \mathrm{~d}$ & $0.00 \mathrm{e}$ & $0.00 \mathrm{c}$ & $0.00 \mathrm{e}$ & $0.11 \mathrm{e}$ \\
993104-10 & $\mathrm{R}$ & $0.02 \mathrm{~g}$ & $0.00 \mathrm{~d}$ & $0.00 \mathrm{e}$ & $0.00 \mathrm{c}$ & $0.00 \mathrm{e}$ & $0.12 \mathrm{e}$ \\
993186-5 & $\mathrm{R}$ & $0.05 \mathrm{~g}$ & $0.00 \mathrm{~d}$ & $0.00 \mathrm{e}$ & $0.04 \mathrm{c}$ & $0.00 \mathrm{e}$ & $0.21 \mathrm{e}$ \\
993111-7 & $\mathrm{R}$ & $0.00 \mathrm{~g}$ & $0.00 \mathrm{~d}$ & $0.00 \mathrm{e}$ & $0.00 \mathrm{c}$ & $0.00 \mathrm{e}$ & $0.00 \mathrm{e}$ \\
CLN2037B & $\mathrm{C}$ & $0.78 \mathrm{e}$ & $0.09 \mathrm{~cd}$ & $0.76 \mathrm{de}$ & $0.21 \mathrm{bc}$ & $0.78 \mathrm{~cd}$ & $2.04 \mathrm{bc}$ \\
CLN2037E & $\mathrm{C}$ & $0.36 \mathrm{f}$ & $0.00 \mathrm{~d}$ & $0.62 \mathrm{de}$ & $0.00 \mathrm{c}$ & $0.22 \mathrm{de}$ & $0.97 \mathrm{~d}$ \\
Error mean square & & 0.25 & 0.09 & 0.49 & 0.13 & 0.29 & 0.26 \\
Minimum significant difference & & 0.26 & 0.35 & 0.81 & 0.42 & 0.63 & 0.58 \\
\hline
\end{tabular}

${ }^{\mathrm{z}}$ Analysis performed upon the natural log of diseased leaflet area.

y $\mathrm{S}=$ susceptible checks, $\mathrm{R}=$ resistant fixed CU-R lines, $\mathrm{C}=\mathrm{CLN}-\mathrm{R}$ lines (CU-R and CLN-R = two independently bred sets of tomato lines developed using $\mathrm{L} 3708$ as a source of late blight resistance), $\mathrm{F}_{1}=$ heterozygous $\mathrm{F}_{1}$ hybrid between resistant fixed CU-R lines $\mathrm{x}$ susceptible checks, $\mathrm{R} \times \mathrm{R}=$ homozygous $\mathrm{F}_{1}$ hybrid between resistant fixed CU-R lines.

${ }^{\mathrm{x}} \alpha=0.05, \mathrm{~N}=90$, error $\mathrm{df}=1050$, critical value of Studentized range $=4.75$.

${ }^{\mathrm{w}} \alpha=0.05, \mathrm{~N}=18$, error $\mathrm{df}=240$, critical value of Studentized range $=4.90$.

diseased area followed a similar pattern (Table 3), with both CLN-R lines differing from the resistant fixed CU-R lines for isolate US-7, while 'CLN2037B' differed from the CU-R lines for isolate NC-1. The results of sporangium number/diseased area $\left(\mathrm{cm}^{2}\right)$ were the same as those for sporangium number [Kim, 2003 (data not shown)].

The data sets of the CLN-R lines and the homozygous CU-R lines were considered as a data subset, with and without subdividing by isolate, and reanalyzed to consider the differences among lines derived from L3708. In this analysis (Table 4), the number of sporangia found on both of the CLN-R lines differed significantly from the number on the CU-R lines. However, this was not due to all isolates having the same response. The number of sporangia found on both of the CLN-R lines differed significantly from the number on the CU-R lines for US-17 and US-7 infection, but did not differ when infection was due to isolates US-11 or DR4B.

SCREening additional CLN-R Lines and RFLP analysis. One explanation for the different response of the CLN-R lines might be that they were segregating or assorting for the resistance, rather than being fixed. To test this possibility, two selections each from 'CLN2037B' and 'CLN2037E' were self-pollinated and the resulting progeny were tested against US-17 by the leaflet dipping method. Also tested were the susceptible controls, the homozygous CU-R lines as resistant controls and seven additional CLN-R lines ('CLN2037A', 'CLN2037C', 'CLN2037D', 'CLN2037F', 'CLN2037G', 'CLN2037H', 'CLN2037I'). The samples from the susceptible controls showed complete spread of the disease as expected, and the homozygous CU-R lines gave the expected resistant response. The four 'CLN2037B' and 'CLN2037E' progeny and the seven CLN-R lines uniformly showed reduced late blight resistance as had been observed in initial tests, indicating that the CLN-R lines were not segregating. Subsequently, the CU-R and CLN-R lines were also included in
RFLP blots probed using TG591, a marker identified as being near the Ph-3 locus (Chunwongse et al., 2002). All lines were homozygous for an S. pimpinellifolium introgression from L3708 for the region including $P h-3$.

GENETIC TESTS. To test the genetic basis for the difference in late blight resistance among lines derived from L3708, plants of a (CLN-R x CU-R) $F_{1}$ hybrid and its parents were inoculated with US-17. Average numbers of sporangia/leaflet produced by CU-R 993186, CLN2037B, and the hybrid 'CLN2037B' $x$ CU-R ' 993186 ' were $1.09,9.68$, and 9.42, respectively. Since a Tukey's Studentized range (honestly significant difference) test calculated a minimum significant difference of 2.55 , the average numbers of sporangia/leaflet of CLN2037B, and the hybrid 'CLN2037B' x CU-R '993186' were not significantly different, but were both significantly higher than that of CU-R ' 993186 '.

The $\mathrm{F}_{2}$ population created by selfing the (CU-R $\times$ CLN-R) $\mathrm{F}_{1}$ hybrid, and controls, were subsequently tested using US-17. Again the CU-R and CLN-R parents showed differential response to this isolate; the $\mathrm{F}_{2}$ population segregated 69 plants with response similar to the CU-R parent and 75 plants with response similar to the CLN-R parent. This segregation ratio does not fit a monogenic 3:1 ratio $\left(\chi^{2}=40.3, P<0.00\right)$, but rather a digenic 7:9 ratio $\left(\chi^{2}\right.$ $=1.02, P=0.314)$.

\section{Discussion}

The characterization of a new source of disease resistance and the lines bred from it is critical to production and deployment of resistant cultivars for disease control. By challenging plants with a variety of pathogen isolates differences in the function and use of the resistance can be determined. When found, these differences can be exploited to better understand the genetic factors contributing to the control of resistance, as well as used to develop breeding strategies that optimize the resistance. 
Table 4. Tukey's Studentized range (honestly significant difference) test of late blight disease response as measured by average sporangium numbers ${ }^{z}$ generated from detached leaflet droplet tests of five CU-R and two CLN-R tomato genotypes (CU-R and CLN-R = two independently bred sets of tomato lines developed using L3708 as a source of late blight resistance) with five pathogen isolates.

\begin{tabular}{lccccccc}
\hline Genotype name & Class $^{\mathrm{y}}$ & All isolates $^{\mathrm{x}}$ & US-11 $^{\mathrm{w}}$ & US-17 $^{\mathrm{w}}$ & DR4B $^{\mathrm{w}}$ & NC-1 $^{\mathrm{w}}$ & US-7w $^{\mathrm{w}}$ \\
\hline $993104-10$ & $\mathrm{R}$ & $0.11 \mathrm{c}$ & $0.00 \mathrm{a}$ & $0.00 \mathrm{~b}$ & $0.00 \mathrm{a}$ & $0.00 \mathrm{~b}$ & $0.54 \mathrm{c}$ \\
$993141-7$ & $\mathrm{R}$ & $0.08 \mathrm{c}$ & $0.00 \mathrm{a}$ & $0.00 \mathrm{~b}$ & $0.00 \mathrm{a}$ & $0.00 \mathrm{~b}$ & $0.40 \mathrm{c}$ \\
$993104-10 \times 993141-7$ & $\mathrm{R} \times \mathrm{R}$ & $0.36 \mathrm{c}$ & $0.00 \mathrm{a}$ & $0.00 \mathrm{~b}$ & $0.00 \mathrm{a}$ & $0.93 \mathrm{~b}$ & $0.86 \mathrm{c}$ \\
$993186-5$ & $\mathrm{R}$ & $0.29 \mathrm{c}$ & $0.00 \mathrm{a}$ & $0.00 \mathrm{~b}$ & $0.52 \mathrm{a}$ & $0.00 \mathrm{~b}$ & $0.94 \mathrm{c}$ \\
$993111-7$ & $\mathrm{R}$ & $0.00 \mathrm{c}$ & $0.00 \mathrm{a}$ & $0.00 \mathrm{~b}$ & $0.00 \mathrm{a}$ & $0.00 \mathrm{~b}$ & $0.00 \mathrm{c}$ \\
CLN2037B & $\mathrm{C}$ & $3.70 \mathrm{a}$ & $0.47 \mathrm{a}$ & $3.81 \mathrm{a}$ & $0.98 \mathrm{a}$ & $3.82 \mathrm{a}$ & $9.40 \mathrm{a}$ \\
CLN2037E & $\mathrm{C}$ & $1.88 \mathrm{~b}$ & $0.00 \mathrm{a}$ & $2.64 \mathrm{a}$ & $0.00 \mathrm{a}$ & $1.85 \mathrm{ab}$ & $4.90 \mathrm{~b}$ \\
Error mean square & & 4.54 & 0.57 & 5.99 & 1.92 & 5.58 & 8.63 \\
Minimum significant difference & 0.94 & 0.76 & 2.45 & 1.39 & 2.37 & 2.94 \\
\hline
\end{tabular}

${ }^{\mathrm{z} A n a l y s i s ~ p e r f o r m e d ~ u p o n ~ t h e ~ n a t u r a l ~ l o g ~ o f ~ d i s e a s e d ~ l e a f l e t ~ a r e a . ~}$

$\mathrm{y} \mathrm{R}=$ resistant fixed CU-R lines, $\mathrm{C}=\mathrm{CLN}-\mathrm{R}$ lines, $\mathrm{R} \times \mathrm{R}=$ homozygous $\mathrm{F}_{1}$ hybrid between resistant fixed CU-R lines.

${ }^{\mathrm{x}} \alpha=0.05, \mathrm{~N}=90$, error $\mathrm{df}=525$, critical value of Studentized range $=4.19$.

${ }^{\mathrm{w}} \alpha=0.05, \mathrm{~N}=18$, error $\mathrm{df}=105$, critical value of Studentized range $=4.25$.

Using detached leaf assays, we were able to conduct a series of experiments that investigated resistance to multiple isolates using the same plant. This assay method also allowed us to test, within the confines of a laboratory, isolates that could not be used in a field trial due to the potential for release into new locales, or because the isolate was of the opposite mating type of the local pathogens. By comparing detached leaf inoculations and field inoculations using the US-17 and US-7 isolates, we have shown that the two methods are equivalent in tests of the CU-R lines, the $P h-1$ and $P h-2$ lines and susceptible controls.

COMPARISON OF REACTIONS FROM FIVE ISOLATES ACROSS TOMATO GENOTYPES USED. Detached leaf assays of lines, hybrids, and controls demonstrated significant differences among the tomato genotypes and against five isolates for average diseased leaflet area and average sporangium number. Susceptible controls were all highly susceptible to all pathogen isolates, confirming susceptibility of these genotypes and indicating the uniformity and severity of disease attainable using this assay. The severe disease levels of the $P h-l$ line 'New Yorker' across isolates was as expected since the $P h-1$ resistance is limited to race-O of the pathogen. Disease level in the $P h-2$ line 'West Virginia 63' was also similar to the susceptible controls when tested with isolates US-7, DR4B, and NC-1. However, this line showed less susceptibility against isolates US-11 and US-17, indicating some difference in the pathogenicity of these two isolates compared to the other three. It also indicated the difference in the resistance of $P h-2$ compared to that possessed by the CU-R or CLN-R lines.

In the homozygous condition, the resistance in the CU-R lines was complete for at least five separate isolates from different regions of the United States and the Dominican Republic. An $F_{1}$ hybrid created by crossing two of the CU-R lines homozygous for late blight resistance was also fully resistant to the five pathogen isolates, as expected since it is homozygous for resistance like its parents. However, for heterozygous $\mathrm{F}_{1}$ hybrids created by crossing a susceptible tomato line with one of the fixed CU-R lines, the disease response was dependent on the isolate tested. The resistance appeared dominant when the heterozygous $\mathrm{F}_{1}$ hybrids were inoculated with US-11. However, when US-17, NC-1, and DR4B were the test isolates, the heterozygous $F_{1}$ hybrids produced a partial dominant resistance response, and when the US-7 isolate was used, the resistance response appeared recessive. Therefore, if we assumed that the resistance was controlled by a single gene, we could not characterize this resistance as being either dominant or recessive; the perceived dominance appears to be a feature of the combination of the plant genotype/pathogen isolate examined, rather than a fixed feature of the resistance genes alone.

The disease response of the CLN-R and fixed CU-R lines were very different, indicating that the resistance carried by these two sets of lines was different. Two CLN-R lines showed responses similar to that of the CU-R lines when inoculated with pathogen isolates DR4B, NC-1, and US-11, but had higher numbers of sporangia and greater areas of disease when inoculated with isolates US-7 or US-17. Possible explanations for this observation were that the CLN-R lines were either still segregating for the resistance, or that the resistance was governed by more than one gene, which was lacking in the CLN-R line. If the CLN-R lines were still segregating for resistance gene(s), then at least some progeny of these lines should include off-type individuals, such as plants with the higher resistance to all five isolates, or plants fully susceptible to these isolates. Such off-type plants were not observed in the progeny of any of the CLN-R lines, indicating that these lines were fixed for their level of resistance rather than segregating for resistance/susceptibility. Furthermore, seven additional CLN-R lines display a similar pattern of partial resistance to US-17, as did the first two CLN-R lines tested. If the CLN-R lines were homozygous for the resistance gene(s), one would not be able explain the differences in the disease response observed between the homozygous CU-R lines and the CLN-R lines. Therefore, the results support the hypothesis that more than one gene is involved in the late blight resistance in the CU-R lines, and that at least one of the resistance genes other than $P h-3$ is absent from the CLN-R line.

GENETIC TESTS. The program that bred the CLN lines reported that resistance in L3708 was controlled by a single, incompletely dominant race-specific gene, $P h-3$, associated with an L3708 introgression near the end of the long arm of chromosome 9 (Chunwongse et al., 2002). Each of the CLN lines and CU-R lines possess an introgression carrying $P h-3$, supporting the map location of $P h-3$ determined by Chunwongse et al. (2002). Differences observed between the CU-R and CLN lines provided an opportunity to test for the action of genes other than $P h-3$ that are involved in resistance to $P$. infestans isolates. The CU-R and CLN-lines, their $\mathrm{F}_{1}$ hybrid and the resulting $\mathrm{F}_{2}$ progeny are all homozygous for $P h-3$, therefore, any difference in the resistance of the two parents and the $\mathrm{F}_{1}$ hybrid, along with the segregation for this difference in the $\mathrm{F}_{2}$, must be due to action of gene(s) other 
than to $P h-3$. The similar level of sporangial production between the $F_{1}$ and the CLN-R parent indicates that at least one recessive gene is involved in the higher level of pathogen resistance observed for the CU-R lines. The 9 to 7 (9:7) segregation ratio of the $\mathrm{F}_{2}$ progeny suggests that the resistance found in the CU-R lines requires a homozygous recessive genotype at one or more genes other than the non-segregating $P h-3$ gene, and that these additional genes are not linked to $P h-3$. These results were consistent with the segregation of resistance to US-7 and US-17 that we observed when breeding the CU-R lines (Kim and Mutschler, 2005), which indicated that resistance to these isolates required one or more recessive genes. The involvement of more than one gene in CU-R might explain why the heterozygous hybrids were neither uniformly dominant nor recessive for resistance. For instance, if resistance to an isolate, such as US-11, required only the dominant $P h-3$ gene, then the heterozygous hybrid produced using a CU-R line would also be resistant. However, when resistance to an isolate, such as US-7, required genes in addition to the $P h-3$ gene, the heterozygous hybrid produced using a CU-R line was not resistant.

Although the data indicate that more than $P h-3$ is involved in the resistance across the five CU-R lines to the five pathogen isolates tested, it does not indicate which parent was the parental source of the additional late blight resistance gene(s) hypostatic to $P h-3$. The segregation observed in breeding for the resistance did not indicate that the hypostatic gene(s) provided strong resistance to any resistance of the isolates used in the breeding screens in the absence of the epistatic gene, $P h-3$. It is possible that the hypostatic gene(s) was derived from L3708, but it is equally likely that it was derived from ' $\mathrm{NC} 215 \mathrm{E}$ '. $\mathrm{BC}_{1} \mathrm{~F}_{2}$ selections derived by crosses of 'NC215E' and L3708 were the source of resistance for both of the CU-R lines and for the late blight-resistant freshmarket tomato lines developed by R. Gardner. These fresh-market tomato lines possessed the same degree of resistance as the CU$\mathrm{R}$ processing tomato lines in both based on lab tests (M.J. Kim and M.A. Mutschler, unpublished) and field trials (R. Gardner, personal communication). 'NC215E' does not appear to be late blight resistant in detached leaflet tests; however, the pedigree of 'NC215E' includes the Solanum habrochaites S. Knapp \& D.M Spooner (syn. Lycopersicon hirsutum Dunal) accession PI126445, which carries mild degree of late blight resistance as well as being the source of the early blight resistance in 'NC215E' (R. Gardner, personal communication). Once the hypostatic genes have been mapped, it may be possible to determine their source.

IMPLICATION FOR BREEDING FOR THE $\boldsymbol{P h}$-3 RESISTANCE COMPLEX. Considered together, our results show that the resistance of L3708 can be transferred to create tomato lines, such as the CU-R lines, which are resistant to multiple pathogen isolates. The most important factor in breeding lines with broad resistance to late blight is to screen using multiple isolates, including isolates such as US-7 which require the complete resistance complex for disease control, rather than isolates controlled by the presence of $P h-3$ alone. The breeding programs that produced the CU-R and CLN-R lines used essentially the same breeding strategies. However, the CLN lines were first selected using isolates of the US-1 clonal lineage, with later tests using isolates of the US-11 clonal lineage, after it had entered Taiwan (AVRDC, 2002). The inclusion of additional resistance genes in the CU-R lines is most likely the fortuitous outcome of the availability and use of the isolates US-7 and US-17 in the selection process.

Since the isolate used for screening is critical to the transfer of the broadest resistance, it is essential that the action of each isolate be tested before use in a screen. The results in Fig. 1 demonstrate a simple but effective means of doing this. The CU-R lines control disease across all isolates tested, but the heterozygous hybrids created by the cross of susceptible tomato line and a CU-R line does not. Thus, testing the resistance of a tomato line to an isolate, along with the heterozygous hybrid derived from that line as a control, would address the reliability of using the isolate in future screens. For instance, if the heterozygous hybrid is not as resistant as the resistant parent, it demonstrates that the isolate being tested is capable of selecting plants with full resistance, so the screen with this isolate is fully informative. If the heterozygous hybrid is as resistant to an isolate as the CU-R parent, it is likely that many of the plants selected as resistant do not carry resistance genes for a spectrum of isolates, so a screen with this local isolate is not as informative.

If the proper isolate is used in detached leaflet assays, careful consideration of the disease response can allow the breeder to utilize the incompletely dominant nature of the resistance to select for plants that are homozygous for the resistance. Using this method, one cycle of the CU breeding population resulted in selection of resistant plants all of which, when that, based on progeny tests, were not only resistant, but also fixed for the resistance. R. Gardner has also been able to select for homozygous resistance using this method (R. Gardner, personal communication).

Detached leaflet assays can be used to screen for transfer of late blight resistance (Kim and Mutschler, 2005), however, this requires considerable labor making it an expensive method. Field screening with inoculation can also be effective, though tests can fail if weather conditions are not conducive to disease. In addition, field screening requires maintenance and production of sufficient inoculum, and the potential for release of a new pathogen isolate into a region must be considered (Kim and Mutschler, 2005). Screening in the field with natural infection depends both on the weather conditions and on the nature of the isolate currently present at that location.

Prior mapping of $P h-3$ by Chunwongse et al. (2002) enabled us to screen for this allele by RFLP (Kim and Mutschler, 2005), and also to develop a PCR-based marker linked to Ph-3 (M.J. Kim and M.A. Mutschler, unpublished data). The use of either RFLP or the PCR marker could reduce the size of the populations requiring isolate screening, since only homozygous plants would require further screening. This could increase breeding efficiency and reduce costs, regardless of the screening method used. However, this does not negate the need for an isolate, such as US-7, to select for the additional resistance genes. Therefore, we are currently using a $(\mathrm{CU}-\mathrm{R} \times \mathrm{CLN}-\mathrm{R}) \mathrm{F}_{2}$ segregating population to try to map the additional resistance genes and permit the development of markers to facilitate their selection.

IMPLICATION FOR DEPLOYMENT OF $\boldsymbol{P} \boldsymbol{h}-\mathbf{3}$ RESISTANCE COMPLEX. The results of this study also suggest the issues that need consideration in deploying $P h-3$ resistance. The differing pathogen resistances observed for the various lines and hybrids demonstrates that it would not be desirable to commercialize cultivars based solely on the $P h-3$ gene. Such cultivars would have strong resistance to isolates such as US-11, but not to isolates like US-7 or US-17. These cultivars would be at greater risk of disease from isolates that can already overcome $P h-3$ alone. For the same reasons, heterozygous hybrid cultivars, comparable to a susceptible line crossed with a CU-R line, would not be as reliable as a fully homozygous line or hybrid. Even a hybrid similar to a (CU-R $\mathrm{x}$ CLR-N) hybrid, which is homozygous for $P h-3$ but heterozygous for the hypostatic genes, may not have the resistance of a line or 
hybrid that is fully homozygous for the resistance.

Any resistance can be overcome by the introduction or evolution of a new pathogen isolate. A new isolate of P. infestans that overcomes the $P h-3$ resistance complex under field conditions was found in North Carolina (R. Gardner, personal communication). This isolate also overcomes the $P h-3$ resistance complex in a detached leaf assay (M.J. Kim and M.A. Mutschler, unpublished). However this isolate does not cause disease on lines possessing only $P h-2$. This new isolate is currently limited to North Carolina, however lines combining both $P h-2$ and $P h-3$ have been developed. Late blight has not yet been observed on these new lines under lab or field conditions.

\section{Literature Cited}

Asian Vegetable Research and Development Center. 1994. 1993 Progress report. Asian Vegetable Research and Development Center, Shanhua, Tainan, Taiwan.

Asian Vegetable Research and Development Center. 1998. 1997 Progress report. Asian Vegetable Research and Development Center, Shanhua, Tainan, Taiwan.

Asian Vegetable Research and Development Center. 1999. 1998 Progress report. Asian Vegetable Research and Development Center, Shanhua, Tainan, Taiwan.

Asian Vegetable Research and Development Center. 2002. 2001 Progress report. Asian Vegetable Research and Development Center, Shanhua, Tainan, Taiwan.

Bonde, R. and E.F. Murphy. 1952. Resistance of certain tomato varieties and crosses to late blight. Maine Agr. Expt. Sta. Bul. 497.

Boodley, J.W. and R.J. Sheldrake. 1973. Cornell peat-like mixes for commercial plant growing. New York Agr. Expt. Sta. Agr. Info. Bul. 43.

Caten, C.E. and J.L. Jinks. 1968. Spontaneous variability of single isolates of Phytophthora infestans. I. Cultural variation. Can. J. Bot. 46:329-348.

Chunwongse, J., C. Chunwongse, L. Black, and P. Hanson. 2002. Molecular mapping of the $\mathrm{Ph}-3$ gene for late blight resistance in tomato. J. Hort. Sci. Biotechnol. 77:281-286.

Conover, R.A. and J.M. Walter. 1952. Heritability resistance to late blight of tomato. Phytopathology 42:197-199.

Conover, R.A. and J.M. Walter. 1953. The occurrence of a virulent race of Phytophthora infestans on late blight resistant tomato stocks. Phytopathology 43:344-345.

Davis, R.M., G. Hamilton, W.T. Lanini, and T.H. Spreen. 1996. The importance of pesticides and other pest management practices in U.S. tomato production. U.S. Dept. Agr., Natl. Agr. Pesticide Impact Assessment Program, Document No. 2-CA-96.

Davis, R.M., G. Hamilton, W.T.Lanini, T.H. Spreen, and C. Osteen. 1998. The Importance of pesticides and other pest management practices in U.S. tomato production. U.S. Dept. Agr., Natl. Agr. Pesticide Impact Assessment Program, Document No. 1-CA-98.

Ewing, E.E., I. Simko, C.D. Smart, M.W. Bonierbale, E.S.G. Mizubuti, G.D. May, and W.E. Fry. 2000. Genetic mapping from field tests of qualitative and quantitative resistance to Phytophthora infestans in a population derived from Solanum tuberosum and Solanum berthaultii. Mol. Breeding 6:25-36.

Fraser, D.E., P.B. Shoemaker, and J.B. Ristaino. 1999. Characterization of isolates of Phytophthora infestans from tomato and potato in North Carolina from 1993 to 1995. Plant Dis. 83:633-638.

Fry, W.E. and S.B. Goodwin. 1997a. Resurgence of the Irish potato famine fungus. Bioscience 47:363-371.

Fry, W.E. and S.B. Goodwin. 1997b. Re-emergence of potato and tomato late blight in the United States. Plant Dis. 81:1349-1357.

Gallegly, M.E. 1952. Physiologic races of the tomato late blight fungus. Phytopathology 42:461-462.

Gallegly, M.E. 1960. Resistance to the late blight fungus in tomato. Proc.
Plant Sci. Seminar. Campbell Soup Co., Camden, N.J. p. 113-135.

Goodwin, S.B., C.D. Smart, R.W. Sandrock, K.L. Deahl,Z.K. Punja, and W.E. Fry. 1998. Genetic change within populations of Phytophthora infestans in the United States and Canada during 1994 to 1996: Role of migration and recombination. Phytopathology 88:939-949.

Goodwin, S.B., L.S. Sujkowski, and W.E. Fry. 1995. Rapid evolution of pathogenicity within clonal lineages of the potato late blight disease fungus. Phytopathology 85:669-676.

Kato, M., E.S. Mizubuti, S.B. Goodwin, and W.E. Fry. 1997. Sensitivity to protectant fungicides and pathogenic fitness of clonal lineages of Phytophthora infestans in the United States. Phytopathology 87:973-978.

Kim, M.J. 2003. Characterization of the late blight resistance of Lycopersicon pimpinellifolium accession L3708, and its transfer to elite processing tomato lines. PhD Thesis. Cornell Univ., Ithaca, N.Y.

Kim, M.J. and M.A. Mutschler. 2005. Transfer to processing tomato and characterization of late blight resistance derived from S. pimpinellifolium L3708. J. Amer. Soc. Hort. Sci. 130:877-884

Laterrot, H. 1975. Selection for the resistance to Phytophthora-infestans in tomato. Annales de l'Amelioration des Plantes Paris 25:129-150.

Legard, D.E., T.Y. Lee, and W.E. Fry. 1995. Pathogenic specialization in Phytophthora infestans: Aggressiveness on tomato. Phytopathology 85:1355-1361.

Malcolmson, J. F. and W. Black. 1966. New R genes in Solanum demissum Lindl. and there complementary races of Phytophthora infestans (Mont.) de Bary. Euphytica 15:199-203.

Mizubuti, E.S.G. and W.E. Fry. 1998. Temperature effects on development stages of isolates from three clonal lineages of Phytophthora infestans. Phytopathology 88:837-843.

Moreau, P., P. Thoquet, J. Olivier, H. Laterrot, and N. Grimsley. 1998. Genetic mapping of $P h-2$, a single locus controlling partial resistance to Phytophthora infestans in tomato. Mol. Plant-Microbe Interactions 11:259-269.

Naess, S.K., J.M. Bradeen, S.M. Wielgus, G.T. Haberlach, J.M. McGrath, and J.P. Helgeson. 2000. Resistance to late blight in Solanum bulbocastanum is mapped to chromosome 8. Theor. Appl. Genet. 101:697-704.

Naess, S.K., J.M. Bradeen, S.M. Wielgus, G.T.Haberlach, J.M. McGrath, and J.P. Helgeson. 2001. Analysis of the introgression of Solanum bulbocastanum DNA into potato breeding lines. Mol. Genet. Genomics 265:694-704.

Peirce, L.C. 1970. A Technique for screening tomato plants for single gene resistance to race O Phytophthora-infestans. Plant Dis. Rptr. 54:681-682.

Peirce, L.C. 1971. Linkage tests with $\mathrm{Ph}$ conditioning resistance to race O, Phytophthora infestans. Tomato Genet. Coop. Rpt. 21:30.

Raposo, R., D.W. Wilks, and W.E. Fry. 1993. Evaluation of potato late blight forecasts modified to include weather forecasts: A simulation analysis. Phytopathology 83:103-108.

Tanksley, S.D., M.W. Ganal, J.P. Prince, V.M.C. De, M.W. Bonierbale, P. Broun, T.M. Fulton, J.J. Giovannoni, S. Grandillo, G.B. Martin, R. Messeguer, J.C. Miller, L. Miller, A.H. Patterson, O. Pineda, M.S. Roder, R.A. Wing, W. Wu, and N.D. Young. 1992. High density molecular linkage maps of the tomato and potato genomes. Genetics 132:1141-1160.

Trognitz, F., P. Manosalva, R. Gysin, L.D. Nino, R. Simon, M.D.R. Herrera, B. Trognitz, M. Ghislain, and R. Nelson. 2002. Plant defense genes associated with quantitative resistance to potato late blight in Solanum phureja $\mathrm{x}$ dihaploid S. tuberosum hybrids. Mol. Plant Microbe Interactions 15:587-597.

Turkensteen, L.J. 1973. Partial resistance of tomatoes against Phytophthora infestans, the late blight fungus. PhD Thesis. Univ. of Wageningen, The Netherlands.

Wastie, R.L. 1991. Breeding for resistance, p. 192-224. In: D.S. Ingram and P.H. Williams (eds.). Advances in plant pathology. Academic, London. 